\title{
Waste activated sludge dewaterability: comparative evaluation of sludge derived from CAS and MBR systems
}

\section{Marco Capodici, Giorgio Mannina \& Michele Torregrossa}

To cite this article: Marco Capodici, Giorgio Mannina \& Michele Torregrossa (2016): Waste activated sludge dewaterability: comparative evaluation of sludge derived from CAS and MBR systems, Desalination and Water Treatment, DOI: 10.1080/19443994.2016.1180478

To link to this article: http://dx.doi.org/10.1080/19443994.2016.1180478

曲 Published online: 04 May 2016.

Submit your article to this journal $₫$

Q View related articles ¿

View Crossmark data 


\title{
Waste activated sludge dewaterability: comparative evaluation of sludge derived from CAS and MBR systems
}

\author{
Marco Capodici, Giorgio Mannina*, Michele Torregrossa \\ Dipartimento di Ingegneria Civile, Ambientale, Aerospaziale, dei Materiali (DICAM), Scuola Politecnica, Università degli Studi di \\ Palermo, Viale delle Scienze ed. 8, Palermo 90128, Italy, Tel. +39 09123896556; Fax: +39091 238 60810; \\ email: giorgio.mannina@unipa.it (G. Mannina)
}

Received 13 April 2015; Accepted 20 March 2016

\begin{abstract}
Sludge dewatering represents, nowadays, one of the greatest operational cost to wastewater treatment cycle. Physical-chemical and biological parameters are recognized to influence the sludge dewaterability. However, many authors agree in identifying the sludge origin as one of the main aspect involved in sludge dewaterability. Indeed, the sludge origin such as the processes involved in liquid-solid separation, seriously affect the sludge features. In order to elucidate the key factors influencing the dewaterability process, the present work is aimed to investigate the influence of the treatment plant lay-out on sludge dewaterability. The analyzed sludge samples were derived from four conventional activated sludge and two membrane bioreactor wastewater treatment plants. Experimental investigation was focused to highlight difference in sludge dewaterability derived from the application of European Standards adopted for sludge characterization. The achieved results confirmed the complexity of the inter-relationships between many factors affecting the sludge dewaterability.
\end{abstract}

Keywords: Sludge dewaterability; Activated sludge; MBR; Capillary suction time

\section{Introduction}

Nowadays, waste activated sludge management represents one of the main aspects involved in the entire cycle of wastewater treatment. Indeed, after the solid-liquid separation by sedimentation or filtration operation, an additional separation is required to achieve a reduction in sludge volume to facilitate transport and handling operations [1]. Sludge dewatering, recognized as one of the most complex and

*Corresponding author.

Presented at EuroMed 2015: Desalination for Clean Water and Energy Palermo, Italy, 10-14 May 2015.

Organized by the European Desalination Society. expensive operation involved in wastewater treatment cycle [1-5], requires significant technical as well as economical efforts [6]. As a matter of a fact, $1 \mathrm{t}$ of fresh sludge to be disposed is composed, on average, by $0.25-0.30 \mathrm{t}$ of suspended solids (SS), with a cost for treatment and disposal around $€ 280-470 / t$ [7]. A better understanding of sludge dewatering features, could lead to an improvement in pretreatment approaches focused to enhance the dewaterability efficiency [6]. In detail, Vesilind et al. [8] have defined four different types of water contained in sludge: free

1944-3994/1944-3986 @ 2016 Balaban Desalination Publications. All rights reserved. 
water, interstitial water, vicinal water, and water of hydratation. More in detail, free water can be easily separated by gravitational settling; interstitial water separation can be achieved only by mechanical dewatering devices, such as centrifugation or vacuum filtration; vicinal water, physically bound to solid particles surface, cannot be separated by any mechanical device. Water of hydratation, chemically bound to solid particles surface, can be separated only by heating at temperature above $105^{\circ} \mathrm{C}$ [6]. Thus, dewatering process is mainly focused to separate the bound water content, represented by the sum of interstitial, vicinal, and hydratation water. Several investigations reported that while in high water content condition (over 80\%) the water separation could be achieved with relatively low cost, when the water content decreases under $80 \%$, the energy demand cost, drastically increases [9-11].

Despite several technologies, such as membrane bioreactor (MBR) systems, have been developed with the focus also to reduce the specific sludge production, still mechanical dewatering represents a crucial step to limit the amount of sludge to be disposed [12]. As a matter of a fact, the efficiency of dewatering process is related to many physical-chemical parameters, such as floc structure, particle size, bound water content, surface charge as well as hydrophobicity. However, many authors agree in identifying the sludge origin as one of the main aspect involved in sludge dewaterability $[1,11,13]$.

Sludge dewaterability is significantly affected by operational wastewater treatment plant settings. In detail, there are some key parameters which strongly influence the sludge dewaterability: sludge retention time (SRT), extracellular polymeric substances (EPS), soluble microbial products (SMP), sludge salt content and presence of filamentous bacteria [14-17]. More in detail, activated sludge flocs are mainly composed by water, biomass and EPS, that are highly charged polymers interacting as a gel with water molecules [18]. The EPS can play a significant role in binding organic and inorganic matter enhancing the attachment of bacteria to surfaces [4]. Together with bound water content, the EPSs are considered as the most important parameters affecting sludge dewaterability [6]. However, due to the complex dynamics of sludge matrix it is still challenging to assess the influence played by extracellular organic features on sludge dewaterability [19]. Indeed, some authors report that dewaterability of sludge improves after EPS reduction [20]; on the contrary, some authors [21,22] found that sludge dewaterability initially increases with EPS content but then decreases once EPS content rises over a threshold value, thus rising some controversial in such aspects. Moreover, rheological features (e.g. viscosity), that provide information on sludge structure at macroscale play an important role in the discussed phenomena [6].

In the light of the above discussion, it comes up that several parameters could affect simultaneously the dewatering process. However, a lot of the discussed parameters are strongly related to plant layout. Indeed, the EPS production as well as particle size distribution (PSD) or floc structure is significantly related on wastewater treatment plant (WWTP): conventional activated sludge (CAS) or MBR.

Bearing in mind the above discussion, in order to elucidate the key factors which influence the dewaterability process, the present work aims to investigate the influence exerted by treatment plant lay-out on sludge dewaterability. Particularly, sludge samples drawn from four CASs and two MBRs have been investigated and compared in terms of dewaterability features. Samples were collected from both water line and sludge line (namely, digestion) in order to detect possible sludge differences. Different parameters have been investigated to better understand sludge dewatering: capillary suction time (CST) $[20,23]$ and specific resistance to filtration (SRF) $[24,25]$.

\section{Materials and methods}

\subsection{The investigated case studies}

The sludge samples drawn from four CASs and two MBR plants were investigated according to experimental procedures discussed in the following. In Table 1, the main features of the investigated plants are summarized.

All investigated WWTPs serve combined sewers which convey both domestic and stormwater flows. The investigated WWTPs ranged from 12,000 to 440,000 equivalent inhabitants, thus covering a representative fraction of the conventional treatment plant application. Moreover, two CASs were also equipped with primary sedimentation unit, thus providing a complete outlook of the possible CAS scheme application. The investigated MBR plants were, on the contrary, representative of small communities (up to 30,000 equivalent inhabitants). Further, the WWTPs were also located in places significantly affected by touristic fluctuation. However, sludge samples were drawn during the winter season, and thus not influenced by tourists. From each WWTP, samples (about $20 \mathrm{~L}$ ) were collected from oxidation unit and also from stabilization unit. The collected samples were stored at $4^{\circ} \mathrm{C}$ until the laboratory was reached. 
Table 1

Main features of the investigated WWT plant

\begin{tabular}{llllllll}
\hline WWTP & EI & $\begin{array}{l}\mathrm{AF} \\
\left(\mathrm{m}^{3} \mathrm{~d}^{-1}\right)\end{array}$ & $\begin{array}{l}\text { OLR } \\
\left(\mathrm{kg} \mathrm{BOD} \mathrm{d}^{-1}\right)\end{array}$ & $\begin{array}{l}\mathrm{OV} \\
\left(\mathrm{m}^{3}\right)\end{array}$ & $\begin{array}{l}\mathrm{AV} \\
\left(\mathrm{m}^{3}\right)\end{array}$ & $\begin{array}{l}\text { DV } \\
\left(\mathrm{m}^{3}\right)\end{array}$ & $\begin{array}{l}\text { MLTSS } \\
\left(\mathrm{kg} \mathrm{m}^{-3}\right)\end{array}$ \\
\hline CAS1 & 440,000 & 152,000 & 30.800 & 17,872 & - & $\begin{array}{l}\text { DTTSS } \\
\left(\mathrm{kg} \mathrm{m}^{-3}\right)\end{array}$ \\
CAS2 & 12,000 & & 1,038 & 720 & 700 & 447 & 4.89 \\
CAS3 & 32,000 & 6,400 & 2,080 & 2,800 & 355 & 1,094 & 4.44 \\
CAS4 & 88,000 & 24,000 & 5,280 & 1,200 & - & 2,400 & 6.08 \\
MBR1 & 15,000 & 3,540 & 810 & $660+110^{(*)}$ & 220 & - & 4.03 \\
MBR2 & 30,000 & 6,465 & 1,800 & $1,800+44^{(*)}$ & 1,000 & - & 13.72 \\
\end{tabular}

Notes: $\mathrm{EI}=$ equivalent inhabitants; $\mathrm{AF}=$ average flow; $\mathrm{OLR}=$ organic loading rate; $\mathrm{OV}=$ oxidation volume; $\mathrm{AV}=$ anoxic volume; DV = digestion volume; MLTSS = mixed liquor total suspended solids; DTTSS digestion tank total suspended solids; $\left({ }^{*}\right)$ oxidation tank volume + MBR tank volume.

\subsection{Experimental procedures}

Sludge samples were analyzed for the determination of total suspended solids (TSS) and volatile suspended solids, in accordance with internationals standards [26]. The PSD for each sludge sample has been also carried out by means of Malvern Mastersizer 2000 particle size analyzer. Moreover, the diameter corresponding to 10,60 , and $90 \%(\mathrm{~V} / \mathrm{V})$ of each PSD was determined. Sludge volume index (SVI) and stirred sludge volume index (SSVI) test were performed in accordance with EN 14702-1 and EN 14702-2 standards [27-32]. In detail, SVI was assessed without dilute or concentrate sludge, and thus at the sludge concentration reported in Table 1; conversely, sludge samples used for the SSVI assessment were diluted with tap water until the sludge concentration reached the value of $3.5 \mathrm{~g} \mathrm{SST} \mathrm{L}^{-1}$ as required by the 14702-2. Furthermore, sludge of CAS 2 was concentrated in order to reach the target concentration required to assess the thickenability. Moreover, tests for the determination of CST, SRF, compressibility, drainability, and thickenability were carried out in accordance with international standards (Table 2).

In detail, the CST was measured on fresh samples and it was used as indicator for deriving the proper dosage of poly-electrolytes needed for conditioning the sludge in accordance with scientific literature $[1,33]$. Indeed, a poly-electrolyte cationic (DRYFLOC $442 \mathrm{H}-\mathrm{SNF}$ ) was formerly dissolved in liquid solution with a concentration equal to $1 \mathrm{~g} \mathrm{~L}^{-1}$ and thus dosed in a range from 2 to $30 \mathrm{mg}$ of flocculants per g TSS. After one minute of mixing phase $(200 \mathrm{rpm})$ and $20 \mathrm{~min}$ of flocculation phase (30 rpm), samples of conditioned sludge were collected and investigated for CST. The optimal flocculants dosage was the one corresponding to the minimum value of the achieved CST [34].
The SRF was evaluated in reduced pressure condition and under pressure condition. In detail, the vacuum condition was achieved by means of a vacuum pump $(-50 \mathrm{kPa})$ connected to a Buchner funnel where Whatman 41 (20 $\mu \mathrm{m}$ pore size) filter paper was placed. The under pressure SRF measurements $(50 \mathrm{kPa})$ were achieved connecting an air pressure system to a filtration device realized in accordance with standards [28]. The sludge compressibility was investigated with the same apparatus adopted for the SRF determination under pressure. Four different pressure ranges were applied: 50, 100, 150, and $300 \mathrm{kPa}$. The sludge compressibility coefficient $(S)$ was evaluated in accordance with Eq. (1):

$S_{P_{1}-P_{2}}=\frac{\log \frac{S R F_{2}}{\mathrm{SRF}_{1}}}{\log \frac{P_{2}}{P_{1}}}$

where $S_{P_{1}-P_{2}}$ is the sludge compressibility; $\mathrm{SRF}_{2}$ and $\mathrm{SRF}_{1}$ represent the specific resistance to filtration achieved by applying positive pressure equal to $P_{2}$ and $P_{1}$, respectively; $P_{2}$ and $P_{1}$ are, respectively, the superior and the minor pressure (measured in $\mathrm{kPa}$ ) applied. Particularly, values of the sludge compressibility higher than one indicates an increase in the specific resistance to filtration more than proportional to the pressure, thus indicating a lack of convenience in operating at high pressure. Flocculated sludge drainability was investigated by adopting three filtering medium normally used in full-scale drainage device (filterpress). In detail, the adopted filtering medium, provided from Testori ${ }^{\circledR}$ Group, were P 4422,

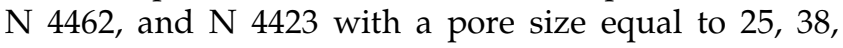
and $49 \mu \mathrm{m}$, respectively. An electronic weighing balance (accuracy $0.001 \mathrm{~g}$ ) was employed for recording the weigh variation each $0.25 \mathrm{~s}$. The sludge thickenability was investigated by stirring ( $1 \mathrm{rpm}$ ) $3.5 \mathrm{~L}$ of sludge for $30 \mathrm{~min}$ in a $50 \mathrm{~cm}$ height cylinder. 
Table 2

Measured parameters and Standard methods applied

\begin{tabular}{|c|c|c|}
\hline Parameter & Document & Reference \\
\hline CST & Characterization of sludge-filtration properties-Part 1: Capillary suction time (CST) & EN 14701-1:2006 \\
\hline SRF & $\begin{array}{l}\text { Characterization of sludge-filtration properties-Part 2: Determination of the specific } \\
\text { resistance to filtration }\end{array}$ & EN 14701-2:2006 \\
\hline Compressibility & $\begin{array}{l}\text { Characterization of sludge-filtration properties-Part 3: Determination of the } \\
\text { compressibility }\end{array}$ & EN 14701-3:2006 \\
\hline Drainability & $\begin{array}{l}\text { Characterization of sludge-filtration properties-Part 4: Determination of the } \\
\text { drainability of flocculated sludge }\end{array}$ & EN 14701-4:2010 \\
\hline SVI & Characterization of sludge-settling properties-Part 1: Determination of settleability & EN 14702-1:2006 \\
\hline Thickenability & $\begin{array}{l}\text { Characterization of sludge-settling properties-Part 2: Determination of } \\
\text { thickenability }\end{array}$ & EN 14702-2:2006 \\
\hline
\end{tabular}

\section{Results and discussion}

In Fig. 1, the mean values of CST, measured for mixed liquor (ML) and for digested sludge (DIG) are reported.

The data reported in Fig. 1 shows that the highest CST takes place for the CAS digested sludge. In general, the CST values for the digested sludge, withdrawn from CAS and MBR, were relatively high and thus indicate poor dewaterability properties. More in detail, the CST for the samples withdrawn from digested sludge is constantly higher, almost double, than the mixed liquor one. Mowla et al. [6] found that the energy required for sludge dewatering increase when sludge water content decrease; as the digested sludge water content is conventionally lower than mixed liquor, the dewaterability of digested sludge resulted more laborious than mixed liquor. Conversely, regarding the mixed liquor, the CST for CAS resulted always lower than the MBR one. The latter circumstance is probably ascribable to the deflocculation effect exerted by the MBR lay-out that significantly affects the dimension of activated sludge

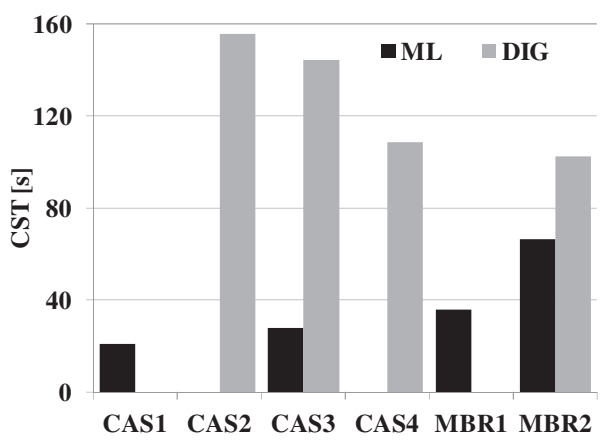

Fig. 1. CST mean values for mixed liquor and digested sludge samples of different WWTPs. flocs $[35,36]$. On the contrary, regarding the CST of the digested sludge, it was found that such value was higher for CAS than MBR. Such a difference is probably ascribable to process parameters involved in the two different treatment schemes. Indeed, it is well known that with the focus to minimize excess sludge production [37], MBR conventionally operate with SRT higher than CAS. Thus, in agreement with AlHalbouni et al. [15], that found that higher SRT leads to sludge with significantly better dewaterability properties compared to sludge with lower SRT, it looks reasonable that the $\mathrm{MBR}$ digested sludge seems to be more easily dewaterable than the CAS digested sludge. In other words, it is characterized by lower CST values. With regards to the sludge floc dimension, in Fig. 2(a) the PSD of the mixed liquor of the investigated samples is plotted. In Fig. 2(b) the main features of each PSD curve are reported.

In detail, Fig. 2(a) and (b) show that MBR flocs are much more thinner than CAS. Particularly, in Fig. 2(b), it is possible to notice that $90 \%$ in volume of the sludge floc has a mean diameter lower than 44$66 \mu \mathrm{m}$ for MBR1 and MBR2, respectively. On the other hand, the minimum value of $d_{90}$ of the investigated CAS was equal to $90 \mathrm{~mm}$. Such observation, which confirms the deflocculating effect exerted by MBR, is in accordance with the CST results. Indeed, the CST results showed a lower measured value for CAS mixed liquor rather than MBR. Shao et al. [19] found that the particle size of the sludge flocs has a significant effect on the CST. Particularly, it was reported that the CST increases when mean particle size of activated sludge decreases. Moreover, Higgins et al. [38] indicated the supracolloidal range size $(1-100 \mu \mathrm{m})$ as the most influencing on sludge dewaterability. Thus, taking into account the PSD, the CAS mixed liquor should be more dewaterable than MBR, but as the dewaterability is also depending on biological aspects 

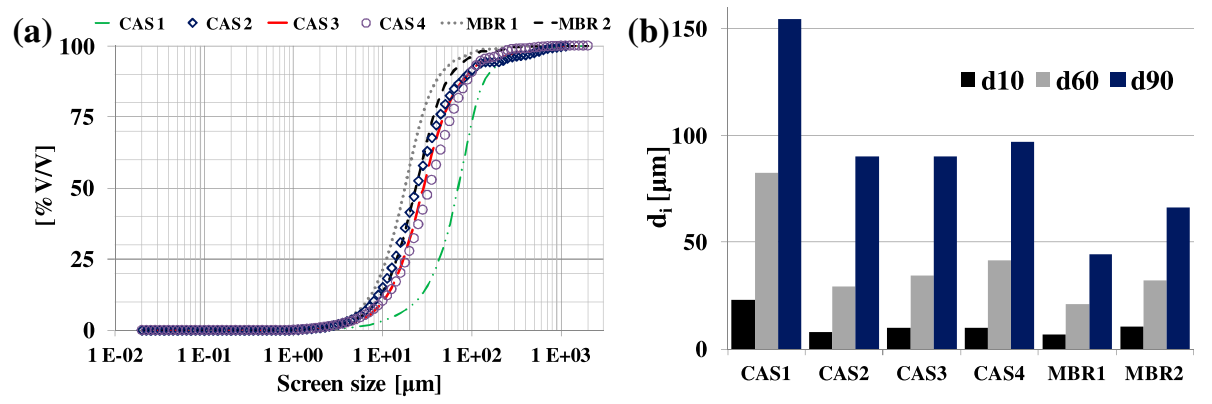

Fig. 2. PSD of mixed liquor samples (a) and main features of each PSD (b).

(e.g. SRT, EPS, and SMP content), the dimensional classification provided by PSD would not represent an exhaustive indicator of sludge dewaterability properties.

Sludge has been conditioned by dosing a poly-electrolyte cationic in accordance with results achieved with CST. In detail the optimal dose for CASs resulted equal to $12 \mathrm{mg}$ of poly-electrolyte $\mathrm{g} \mathrm{SS}^{-1}$ except for CAS1 sample where the optimal dose resulted equal to $10 \mathrm{mg}$ of poly-electrolyte $\mathrm{g} \mathrm{SS}^{-1}$; furthermore the CST corresponding to the optimal dose were equal to $17,32,28$, and $26 \mathrm{~s}$ for CAS 1, 2, 3, and 4, respectively. With reference to MBR, the optimal dose resulted equal to $8 \mathrm{mg}$ of poly-electrolyte $\mathrm{g} \mathrm{SS}^{-1}$ for both MBR 1 and 2 and the corresponding CST resulted equal to 16-18 s for MBR 1 and 2, respectively.

Regarding the SRF in reduced pressure condition, measures were carried out both on unconditioned sludge and on conditioned sludge and results are reported in Fig. 3. Particularly, as sludge filtration is conventionally carried out on the digested sludge, the SRF assessment has been carried out mainly on digested sample. However, for the CAS1 the digested sludge volume available was not sufficient to carry out the SRF and so the mixed liquor was investigated. With reference to both MBR the investigated sludge was the mixed liquor; furthermore as in MBR2 a sludge digestion tank exists, the SRF was also evaluated and is identified as MBR2 $\mathrm{d}$ in the Fig. 3 legend.

It is worth noting that there is not a significant difference with raw samples. Particularly, all the investigated sludge samples are characterized by a SRT value above the threshold value (namely, $5 \times 10^{12} \mathrm{~m} \mathrm{~kg}^{-1}$ ). The threshold value (horizontal dotted red line Fig. 3) has been derived by a recommended value of EN 14701-2 [28]. According to the Standards, below such threshold value, sludge can be considered filterable on industrial scale and thus not well dewaterable by void filtration.

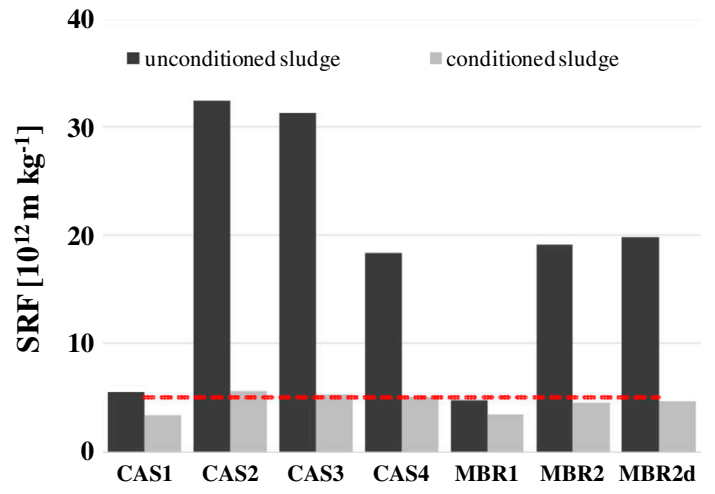

Fig. 3. Reduced pressure SRF for CAS1 mixed liquor, CAS2, CAS3, and CAS4 digested sludge, MBR1 and MBR 2 mixed liquor and MBR 2 digested sludge.

Moreover, the flocculants dosing resulted efficient only with the MBR sludge. Indeed, for the MBR sludge, the SFR reached values below the threshold after the chemical dosing. Conversely, for three sludge of the CASs, the SRF did not decrease below the threshold; thus showing some shortcomings in the sludge filterability. Particularly, the SFR values, measured after chemical conditioning, were equal to $5.62 \times 10^{12} \mathrm{~m} \mathrm{~kg}^{-1}, 5.32 \times 10^{12} \mathrm{~m} \mathrm{~kg}^{-1}$, and $5.07 \times 10^{12} \mathrm{~m} \mathrm{~kg}^{-1}$ for CAS2, CAS3, and CAS4, respectively. The SRF has been investigated also on pressure cell with a positive applied pressure equal to 50, 100, 150 , and $300 \mathrm{kPa}$. The results are reported in Fig. 4(a) and (b). Such results were used to evaluate the sludge compressibility.

The derived results did not highlight significant differences between CAS and MBR. Moreover, even after the chemical conditioning, the SRF values remained almost constantly above the threshold (horizontal dotted red line of Fig. 4) thus demonstrating a scarce sludge filterability on an industrial scale. However, as soon as chemical flocculants was added, the filterability features were improved. Furthermore, 

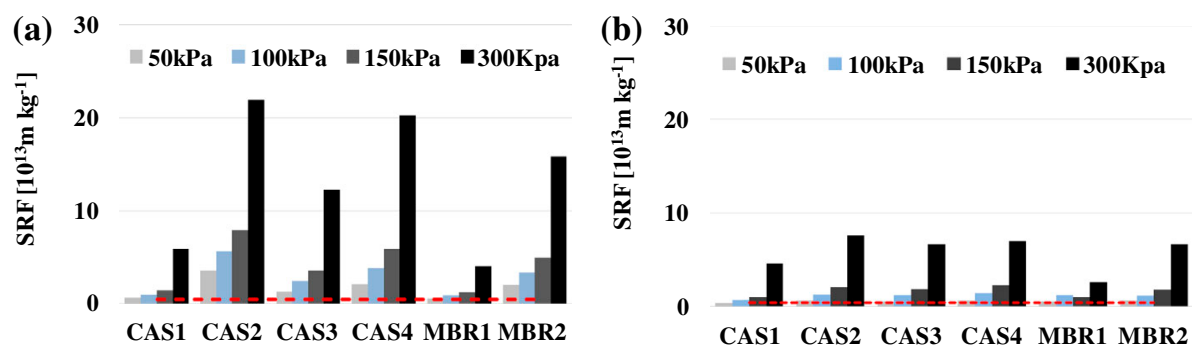

Fig. 4. SRF for unconditioned sludge (a) and conditioned sludge (b).

the achieved SRF results allowed to evaluate the compressibility coefficient $S$ (Table 3 ).

The poor under pressure filterability, highlighted by the SRF results, was confirmed also by the compressibility coefficient evaluated for the investigated sludge. In detail, by increasing the applied pressure, the compressibility coefficient raised up to values above one. More in detail, with reference to $S_{150-300 \text {, }}$ none of the investigated sludge, raw as well as conditioned, resulted compressible under high pressure. However, the derived results highlighted that for low applied pressure $\left(S_{50-100}\right)$ all the raw samples, CAS and MBR, resulted with good compressibility features. Conversely, for the same applied pressure, all the conditioned sludge samples resulted with higher value of $S$, thus indicating that chemical flocculants dosing caused a worsening of the sludge compressibility features contrasting the results achieved for the SRF assessments.

The drainability of the sludge has been evaluated by means of three filtering devices and, as example, in Fig. 5 are reported the results regarding drainability carried out with $38 \mu \mathrm{m}$ filtering device for CAS3 and MBR1.

In detail, despite the chemical conditioning improved sludge drainability features, the results did not highlight significant differences between CAS and MBR sludge. On the contrary, regarding the effect of chemical flocculants dosage, a major effect was observed for MBR sludge. As an example, in Fig. 5(a) the ratio $M_{t}$ vs. $M_{0}$, where $M_{t}$ is the liquid mass filtered after $t$ seconds and $M_{0}$ is the initial mass to be filtered, is plotted vs. time. In Fig. 5(b), the slope of each interpolating line is reported. The ratio $M_{t} / M_{0}$ vs. time provides information about the velocity of the drainage. For the analyzed samples, drainage velocity improved more for MBR sludge than for CAS. Indeed, due to the flocculants effect, drainage velocity for CAS3 was 1.56 time higher than for raw sludge. Conversely, the drainage velocity of MBR1 increased up to 1.98 time higher after chemical conditioning. Such a result, reported as an example, is representative of all the investigated sludge. On average, the drainage velocity after chemical conditioning increased, respect to raw sludge, up to 1.72-1.91 time for CAS and MBR sludge, respectively. Thus, in apparent contrast with the results observed for the compressibility, the drainability of sludge was improved by chemical conditioning.

Regarding sludge settleability ad thickenability features, the achieved values of SVI and SSVI index are summarized in Table 4 .

The reported results, demonstrate the poor settleability features of the investigated sludge. In detail, the derived data indicates bulking phenomena for both MBRs and for CAS2 and CAS3. Such a result is

Table 3

Compressibility for raw and conditioned sludge

\begin{tabular}{|c|c|c|c|c|c|c|c|}
\hline \multirow[b]{2}{*}{ WWTP } & \multirow[b]{2}{*}{ Sample } & \multicolumn{3}{|c|}{ Raw sludge } & \multicolumn{3}{|c|}{ Conditioned sludge } \\
\hline & & $S_{50-100}$ & $S_{100-150}$ & $S_{150-300}$ & $S_{50-100}$ & $S_{100-150}$ & $S_{150-300}$ \\
\hline CAS1 & ML & 0.63 & 1.01 & 2.06 & 0.97 & 0.75 & 2.17 \\
\hline CAS2 & DIG & 0.66 & 0.83 & 1.94 & 0.85 & 1.22 & 1.84 \\
\hline CAS3 & DIG & 0.86 & 0.95 & 1.76 & 1.02 & 1.10 & 1.75 \\
\hline CAS4 & DIG & 0.85 & 1.10 & 1.78 & 1.12 & 1.04 & 1.62 \\
\hline MBR1 & ML & 0.78 & 0.84 & 1.69 & 0.80 & 1.08 & 1.83 \\
\hline MBR2 & DIG & 0.77 & 0.92 & 1.68 & 1.74 & 1.08 & 1.90 \\
\hline
\end{tabular}



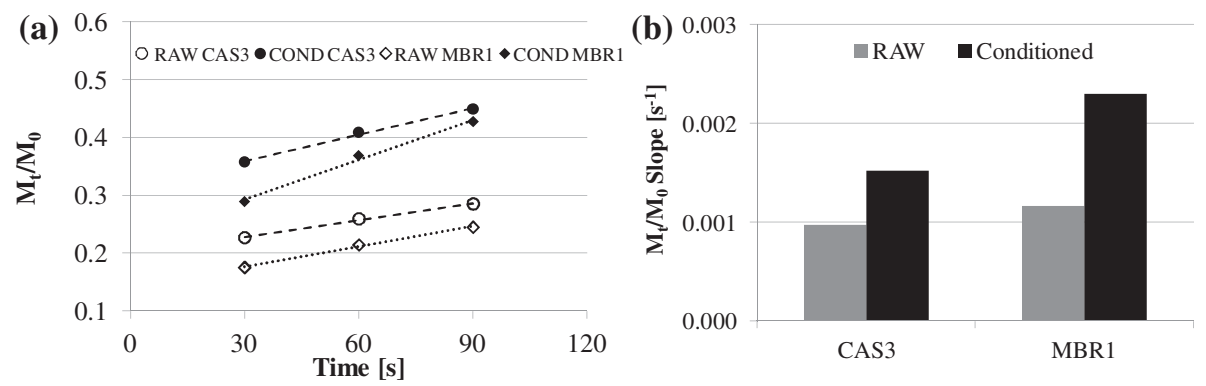

Fig. 5. Drainage with $38 \mu \mathrm{m}$ filtering device (a) and slope of the plotted results (b).

Table 4

SVI and SSVI

\begin{tabular}{lll}
\hline WWTP & $\begin{array}{l}\text { SSV } \\
\left(\mathrm{ml} \mathrm{g}^{-1}\right)\end{array}$ & $\begin{array}{l}\text { SSVI } \\
\left(\mathrm{ml} \mathrm{g}^{-1}\right)\end{array}$ \\
\hline CAS1 & 110 & 55 \\
CAS2 & 270 & 120 \\
CAS3 & 230 & 100 \\
CAS4 & 150 & 60 \\
MBR1 & 270 & 140 \\
MBR2 & 270 & 40 \\
\hline
\end{tabular}

probably due to WWTP operational conditions. Moreover, taking into account the obtained results for the SSVI, significant differences between CAS and MBR sludge were not underlined; indeed the investigated sludge were all characterized by low values of SSVI indicating a good sludge thickenability.

\section{Conclusions}

The activated sludge dewatering certainly represents one of the most crucial and controversial aspect involved in the wastewater treatment managing. Several factors, such as WWTP lay-out, operational parameters, EPS and organic load influence sludge dewaterability. The interaction between the aforementioned factors remains still to be clarified. In the present study, a comparative evaluation of the dewaterability features of sludge samples derived from CASs and MBRs has been carried out. To carry out a comprehensive comparison, the international standards methods conventionally adopted for sludge characterization have been employed.

The obtained results showed a lower CST for MBR digested sludge. On the other hand, different results have been derived with respect to the mixed liquor where the thinner floc dimension, underlined also by the PSD evaluation, was likely the key factor of a worse dewaterability. Moreover, with reference to MBR conditioned sludge, it was found a better suitability to be filtered under reduced pressure (void filtration) condition. The under pressure filtration, investigated with SRF measurements, showed a scarce sludge filterability at high pressure and a poor compressibility of raw sludge as well as conditioned sludge. Controversial results have been obtained regarding the sludge conditioning. As a matter of a fact, while the sludge compressibility was found worsened by chemical flocculants addiction, on the contrary, the drainability of the sludge was improved by the conditioning.

To sum-up, this study confirmed the inter-relationships of the main factors which control/depend the sludge dewaterability (i.e. WWTP lay-out, physicalchemicals, and biological processes). The derived results, allowed to gain insights to better understand the complexity of the sludge dewatering and the necessity to make a comparative evaluation that take into account also the biological aspect and the operative condition as well as the rheological features of the sludge to be dewatered.

\section{Acknowledgments}

This work forms part of a research project supported by grant of the Italian Ministry of Education, University and Research (MIUR) through the Research project of national interest PRIN2012 (D.M. 28 dicembre 2012 n. 957/Ric-Prot. 2012PTZAMC) entitled "Energy consumption and GreenHouse Gas (GHG) emissions in the wastewater treatment plants: a decision support system for planning and management-http://ghgfromwwtp.unipa.it" in which the corresponding author is the Principal Investigator.

\section{References}

[1] B. Jin, B.-M. Wilén, P. Lant, Impacts of morphological, physical and chemical properties of sludge flocs on dewaterability of activated sludge, Chem. Eng. J. 98 (2004) 115-126. 
[2] W.R. Knocke, C.M. Dishman, G.F. Miller, Measurement of chemical sludge floc density and implications related to sludge dewatering, Water Environ. Res. 65 (1996) 735-742.

[3] S.N. Murthy, J.T. Novak, R.D. Dehaas, Monitoring cations to predict and improve activated sludge settling and dewatering properties of industrial wastewaters, Water Sci. Technol. 38(3) (1998) 119-126.

[4] S.N. Murthy, J.T. Novak, Factors affecting floc properties during aerobic digestion: Implications for dewatering, Water Environ. Res. 71(2) (1999) 197-202.

[5] G. Bertanza, M. Papa, M. Canato, M.C. Collivignarelli, R. Pedrazzani, How can sludge dewatering devices be assessed? Development of a new DSS and its application to real case studies, J. Environ. Manage. 137 (2014) 86-92.

[6] D. Al-Halbouni, J. Traber, S. Lyko, T. Wintgens, T. Melin, D. Tacke, A. Janot, W. Dott, J. Hollender, Correlation of EPS content in activated sludge at different sludge retention times with membrane fouling phenomena, Water Res. 42 (2008) 1475-1488.

[7] D. Mowla, H.N. Tran, D. Grant Allen, A review of the properties of biosludge and its relevance to enhanced dewatering processes, Biomass Bioenergy 58 (2013) 365-378.

[8] P. Ginestet, Comparative Evaluation of Sludge Reduction Routes, IWA Publishing, London, UK, 2006.

[9] P.A. Vesilind, C.C. Hsu, Limits of sludge dewaterability, Water Sci. Technol. 36(11) (1997) 87-91.

[10] D.J. Lee, Y.H. Hsu, Measurement of bound water in sludges: A comparative study, Water Environ. Res. 67 (3) (1995) 310-317.

[11] P.C. Chu, D.J. Lee, Moisture distribution in sludge: Effects of polymer conditioning, J. Environ. Eng. 125 (4) (1999) 340-345.

[12] L. Wang, D. He, Z. Tong, W. Li, H. Yu, Characterization of dewatering process of activated sludge assisted by cationic surfactants, Biochem. Eng. J. 91 (2014) 174-178.

[13] M. Marinetti, F. Malpei, L. Bonomo, Relevance of expression phase in dewatering of sludge with chamber filter presses, J. Environ. Eng. 135(12) (2009) 1380-1387.

[14] J.T. Novak, M.E. Sadler, S.N. Murthy, Mechanisms of floc destruction during anaerobic and aerobic digestion and the effect on conditioning and dewatering of biosolids, Water Res. 37 (2003) 3136-3144.

[15] L.H. Mikkelsen, T. Mascarenhas, P.H. Nielsen, Key parameters in sludge dewatering: Testing for the shear sensitivity and EPS content, Water Sci. Technol. 46(10) (2002) 105-114.

[16] D. Al-Halbouni, J. Traber, S. Lyko, T. Wintgens, T. Melin, D. Tacke, A. Janot, W. Dott, J. Hollender, Correlation of EPS content in activated sludge at different sludge retention times with membrane fouling phenomena, Water Res. 42 (2008) 1475-1488.

[17] T.V. Bugge, P. Larsen, A.M. Saunders, C. Kragelund, L. Wybrandt, K. Keiding, M.L. Christensen, P.H. Nielsen, Filtration properties of activated sludge in municipal MBR wastewater treatment plants are related to microbial community structure, Water Res. 47 (2013) 6719-6730.

[18] G. Mannina, A. Cosenza, D. Di Trapani, M. Capodici, G. Viviani, Membrane bioreactors for treatment of saline wastewater contaminated by hydrocarbons (diesel fuel): An experimental pilot plant case study, Chem. Eng. J. 291 (2016) 269-278.

[19] K. Keiding, L. Wybrandt, P.H. Nielsen, Remember the water: A comment on EPS colligative properties, Water Sci. Technol. 43 (2001) 17-23.

[20] L. Shao, P. He, G. Yu, P. He, Effect of proteins, polysaccharides, and particle sizes on sludge dewaterability, J. Environ. Sci. 21 (2009) 83-88.

[21] Y. Chen, H. Yang, G. Gu, Effect of acid and surfactant treatment on activated sludge dewatering and settling, Water Res. 35 (2001) 2615.

[22] J. Houghton, J. Quarmby, T. Stephenson, Municipal wastewater sludge dewatering and the presence of microbial extracellular polymer, Water Sci. Technol. 44 (2) (2001) 373-379.

[23] J. Houghton, T. Stephenson, Effect of influent organic content on digested sludge extracellular polymer content and dewaterability, Water Res. 36 (2002) 3620-3628.

[24] P.A. Veselind, Capillary suction time as a fundamental measure of sludge dewaterability, J. Water Pollut. Control Fed. 60(2) (1988) 215-220.

[25] M. Scholz, Review of recent trends in capillary suction time (CST) dewaterability testing research, Ind. Eng. Chem. Res. 44(22) (2005) 8157-8163.

[26] G. Peng, F. Ye, Y. Li, Comparative investigation of parameters for determining the dewaterability of activated sludge, Water Environ. Res. 83(7) (2011) 667-671

[27] APHA, AWWA, WEF, Standard Methods for the Examination of Water and Wastewater, twentieth ed., American Public Health Association/American Water Works Association/Water Environment Federation, Washington, DC, 1998.

[28] EN 14701-1. European Standard, Characterization of Sludges-Filtration Properties-Part 1: Capillary Suction Time (CST), European Committee for Standardization, Brussels, March 2006.

[29] EN 14701-2. European Standard, Characterization of Sludges-Filtration Properties-Part 2: Determination of the Specific Resistance to Filtration, European Committee for Standardization, Brussels, June 2006.

[30] EN 14701-3. European Standard, Characterization of Sludges-Filtration Properties-Part 3: Determination of the Compressibility, European Committee for Standardization, Brussels, June 2006.

[31] EN 14701-4. European Standard, Characterization of Sludges-Filtration Properties-Part 4: Determination of the Drainability of Flocculated Sludges, European Committee for Standardization, Brussels, January 2010.

[32] EN 14702-1. European Standard, Characterization of Sludges-Settling Properties-Part 1: Determination of Settleability (Determination of the Proportion of Sludge Volume and Sludge Volume Index), European Committee for Standardization, Brussels, March 2006.

[33] EN 14702-2. European Standard, Characterization of Sludges-Settling Properties-Part 2: Determination of Thickenability, European Committee for Standardization, Brussels, March 2006.

[34] O. Sawalha, M. Scholz, Assessment of capillary suction time (CST) test methodolgies, Environ. Technol. 28 (2007) 1377-1386. 
[35] J.T. Novak, M.L. Agerbæk, B.L. Sørensen, J.A. Hansen, Conditioning, filtering, and expressing waste activated sludge, J. Environ. Eng. 125(9) (1999) 816-824.

[36] F. Durante, G. Di Bella, M. Torregrossa, G. Viviani, Particle size distribution and biomass growth in a submerged membrane bioreactor, Desalination 199 (2006) 493-495.
[37] M. Capodici, G. Di Bella, D. Nicosia, M. Torregrossa, Effect of chemical and biological surfactants on activated sludge of MBR system: Microscopic analysis and foam test, Bioresour. Technol. 177 (2015) 80-86.

[38] G. Laera, A. Pollice, D. Saturno, C. Giordano, A. Lopez, Zero net growth in a membrane bioreactor with complete sludge retention, Water Res. 39 (2005) 5241-5249. 